\title{
MULTICULTURALISMO NO ENSINO SUPERIOR: O OLHAR DOCENTE SOBRE A FORMAÇÃO DE PROFESSORES(AS) DE MÚSICA
}

\section{Renan Santiago de Sousa}

Doutorando em Educação pela Universidade Feral do Rio de Janeiro. Mestre em Educação pela mesma instituição. Licenciado em Música pelo Conservatório Brasileiro de Música-Centro Universitário e licenciando em Pedagogia pela Universidade Federal do Estado do Rio de Janeiro. Professor de Música na educação básica. E-mail: holy_renan@yahoo.com.br

\section{RESUMO}

Este artigo tem como objetivo analisar como questões de interesse do multiculturalismo, como raça, etnia, gênero, sexualidade, religiosidade e identidade musical perpassam os discursos de docentes de três cursos de Licenciatura em Música de três Instituições de Ensino Superior da cidade do Rio de Janeiro, a saber, o CBM-CEU, a UNIRIO e a UFRJ. Para tal, foram feitas entrevistas semiestruturadas com 9 docentes das instituições citadas: três com docentes de disciplinas ligadas ao ensino de didática da Música, três voltadas à formação do musicista e três classificadas como disciplinas detentoras de potenciais multiculturais. Pôde-se concluir que a temática das diferenças culturais têm perpassado no currículo de tais instituições e travado embates com o conservadorismo que é característico das faculdades de Música. Porém, o trato das diferenças, quando abordado, ocorre, muitas vezes, somente no âmbito das diferenças de musicalidade, havendo ainda pouco espaço para discussões gerais de tópicos como raça, etnia, sexualidade, gênero, religiosodade etc., por várias questões discutidas durante o texto.

Palavras-chave: Multiculturalismo. Educação Musical. Formação de Professores.

\section{MULTICULTURALISM IN HIGHER EDUCATION: THE PROFESSOR SIGHT AT THE FORMATION OF MUSIC TEACHERS}

\begin{abstract}
This article aims to analyze how issues of interest in multiculturalism such as race, ethnicity, gender, sexuality, religiosity and musical identity permeate the teaching discourses of three Music Licensing courses of three Higher Education Institutions in the city of Rio de Janeiro, namely: CBM-CEU, UNIRIO and UFRJ. For that, semi-structured interviews were carried out with 9 teachers from the above mentioned institutions: three with teachers of disciplines linked to the teaching of Music didactics, three focused on the musician's fortification and three classified as disciplines with multicultural potentials. It could be concluded that the theme of cultural differences have permeated the curriculum of such institutions and clashed with the conservatism that is characteristic of the faculties of Music. However, the treatment of differences, when approached, often occurs only within the scope of differences in musicality, and there is still little space for general discussion of topics such as race, ethnicity, sexuality, gender, religiosity etc. for several issues discussed during the text.
\end{abstract}

Keywords: Multiculturalism. Music Education. Teacher Education.

\section{MULTICULTURALISMO EN LA ENSEÑANZA SUPERIOR: EL MIRAR DEL PROFESORADO SOBRE LA FORMACIÓN DE PROFESORES(AS) DE MÚSICA}

\section{RESUMEN}

Esta ponencia tiene como objetivo analizar como cuestiones de interés del multiculturalismo, como raza, etnia, género, sexualidad, religiosidad e identidad musical están presentes en los discursos de docentes de tres cursos de Licenciatura en Música de tres Instituciones de Enseñanza Superior de la 
ciudad de Río de Janeiro, a saber, el CBM-CEU, la UNIRIO y la UFRJ. Para esto, se realizaron entrevistas semiestructuradas con 9 docentes de las instituciones citadas: tres con docentes de disciplinas ligadas a la enseñanza de didáctica de la Música, tres dirigidas a la formación del musicista y tres clasificadas como disciplinas detentoras de potenciales multiculturales. Se pudo concluir que la temática de las diferencias culturales han pasado en el currículo de tales instituciones y hecho embates con el tradicionalismo que es característico de las facultades de Música. Sin embargo, el trato de las diferencias, cuando abordado, ocurre, muchas veces, sólo en el ámbito de las diferencias de musicalidad, habiendo todavía poco espacio para discusiones generales de tópicos como raza, etnia, sexualidad, género, religiosidad, etc., por muchas cuestiones discutidas durante el texto.

Palabras-clave: Multiculturalismo. Educación Musical. Formación de Profesores.

\section{Introdução: Música na escola e a emergente necessidade de uma educação multicultural}

Em 2008, teve-se o advento da Lei $11.769^{1}$, que impôs como obrigatório o conteúdo "Música" nos currículos escolares da educação infantil ao ensino médio, nos âmbitos das redes pública e privada de ensino (SOBREIRA, 2012; PENNA, 2012; SANTOS, 2012). Dentro desse contexto, diversas pesquisas na área de Música e Educação foram feitas a fim de se entender os diferentes aspectos que são reflexos da promulgação da Lei em questão.

A análise dos artigos que tratam diretamente sobre a Lei tratada publicados em revistas científicas brasileiras especializadas Música e/ou qualificadas no estrato mais alto da avaliação da $\mathrm{CAPES}^{2}$ na área de Artes aponta para algumas categorias tais como: a efetividade do cumprimento da Lei (REQUIÃO, 2013; WOLFFENBÜTTEL; ERTEL; SOUZA, 2016), os processos da sua implementação (LEMOS, 2010; SOUZA et al., 2010; SOBREIRA, 2010, 2012; PENNA, 2013; QUEIROZ, 2012); as necessidades da Música na educação básica (COUTO; SANTOS, 2009); os saberes e conhecimentos utilizados no currículo da disciplinas em questão (PENNA, 2012; SANTOS, 2012), a formação do(a) pedagogo(a) para lecionar Música (FURQUIM; BELLOCHIO, 2010; CUNHA et al, 2009) e a formação do(a) professor(a) especialista em Música (ALVARENGA; MAZZOTI, 2011; JUNIOR, 2015; SANTIAGO; IVENICKI, 2016a).

Nessa perspectiva, o presente artigo busca contribuir com a citada discussão, focando-se no tema da formação de professores(as) especialistas por meio dos cursos de Licenciaturas em Música, com ênfase na questão do tratamento dado por estes as

\footnotetext{
${ }^{1}$ Vale ressaltar que a Lei 11.769/2008 foi modificada em 2016 pela 13.278/2016, passando a incluir também as Artes Visuais, a Dança e o Teatro.

${ }^{2}$ Revista da ABEM, Revista Opus, Revista Música Hodie e Revista Educação e Realidade.
} 
diferenças culturais presentes nas dinâmicas do processo de ensino e aprendizagem das salas de aula da educação básica.

Tal assunto se faz necessário, pois argumenta-se que a escola é um local considerado plural por ser frequentado por diversos grupos socioculturais e tal pluralidade, que deveria em um primeiro vislumbre se constituir em um aspecto inteiramente positivo, pode acarretar fenômenos negativos, tais como racismos, sexismos, machismos, xenofobias, intolerâncias religiosas, bullyings etc., não pela pluralidade em si, mas pelas relações de poder e disputas políticas que são oriundas dos embates entre diferentes grupos sociais (CANEN; MOREIRA, 2001; CANEN et al, 2001; CANEN; ANDRADE, 2005).

Portanto, se argumenta que a Lei 11.769/2008, ao facilitar a entrada da Música no cotidiano escolar, também tensiona a área da educação (musical) a tecer reflexões sobre como ensinar Música de forma tal com que as diferenças culturais sejam respeitadas e que os diversos tipos de preconceitos e discriminações sejam desestimulados por meio de uma educação musical pós-moderna. Nessa perspectiva, apresenta-se o multiculturalismo como um ideário propício à realização de tal intento (PENNA, 2005, 2006; LAZZARIN, 2006, 2008; SANTIAGO; IVENICKI, 2016a).

De forma simplória, pode-se conceituar multiculturalismo como uma resposta às questões que emergem dos choques e entrechoques culturais na sociedade contemporânea (SANTIAGO; IVENICKI, 2016b). Tal ideário se constitui, portanto, em um conjunto de ideias e ações que buscam reconhecer, celebrar e valorizar as diferenças, reconhecendo culturas marginalizadas e estereotipadas, buscando incorporá-las no cotidiano escolar sem deixar de denunciar as relações de poder que originam os preconceitos e discriminações (CANEN apud BATISTA et al., 2013). Nessa perspectiva, o presente trabalho tem como objetivo analisar como temas de interesse do multiculturalismo como raça, gênero, sexualidade, religiosidade e identidade musical estão presentes na formação de professores(as) de Música, sob o olhar do(a) professor(a) formador(a).

A fim de se realizar uma análise mais focada, a pesquisa delimitou-se na cidade do Rio de Janeiro. Tal região foi eleita por, após a Lei tratada no texto, promulgar um número significativo de concursos públicos com vagas para professores(as) de Música (SANTIAGO, 2017; FIGUEIREDO; MEURER, 2016), o que parece apontar que, em tal 
cidade, a Música tem passado por um processo de disciplinarização ${ }^{3}$ nas escolas públicas ou seja, a tal área do saber tem se tornado uma disciplina escolar e não um mero conteúdo curricular, como aponta a Lei - e o perfil do(a) docente que tem ministrado tais aulas é de uma pessoa formada em uma licenciatura específica.

Seguindo tal raciocínio, justifica-se a importância de se analisar a formação oferecida pelas Licenciaturas em Música na cidade supracitada, visto que elas têm exercido um papel central na formação de professores(as) que atuam ou irão atuar nas salas de aula da educação básica.

Desse modo, a pesquisa se deu em três instituições que oferecem o curso de Licenciatura em Música na cidade do Rio de Janeiro: o Conservatório Brasileiro de Música -Centro Universitário (CBM-CEU), o Instituto Villa-Lobos do Centro de Letras e Artes da Universidade Federal do Estado do Rio de Janeiro (IVL/CLA/UNIRIO) e a Escola de Música da Universidade Federal do Rio de Janeiro (EM/UFRJ). Tais instituições foram eleitas por serem as mais tradicionais na cidade citada, sendo amplamente reconhecida pela excelência no ensino e por contribuirem maciçamente com a formação de professores(as) de Música na cidade em questão.

Para se coletar os dados, foi utilizada a metodologia de entrevistas semiestruturadas (BONI; QUARESMA, 2005) com um total de nove docentes, três de cada instituição. Em suma, pretendeu-se entender e categorizar os discursos docentes sobre a atuação das Licenciaturas em Música na cidade do Rio de Janeiro no que se refere à formação de professores(as) de Música para atuarem com as diferenças culturais presente nas salas de aula da educação básica. Tal discussão se iniciará a partir do próximo subtópico, apresentando, inicialmente, o roteiro de perguntas utilizado.

\section{Entrevistas: Metodologia e roteiro}

Para se escolher os(as) docentes que seriam entrevistados(as), optou-se por focar a pesquisa em três disciplinas: uma voltada para o "ensinar a ensinar" Música, outra voltada para a formação do músico e uma terceira classificada como "detentora de potenciais multiculturais", ou seja, que tivesse potencial para, direta ou indiretamente, tratar de temas

\footnotetext{
${ }^{3}$ Tal processo é decorrente da realidade gerada pela Lei 11.769/2008 cujo conteúdo dissertava somente sobre o ensino do conteúdo "Música". Não se pretende afirmar que tal disciplinarização vai continuar ocorrendo após a Lei 13.278/2016, que inclui mais três linguagens artísticas.
} 
de interesse do multiculturalismo, como raça, etnia, sexualidade, gênero etc. (CANEN et al., 2001).

Nessa perspectiva, foram escolhidas as disciplinas de Didática da Música (conhecida como Processos de Musicalização na UNIRIO), Percepção Musical e mais três disciplinas classificadas como detentoras de potenciais multiculturais: História da Cultura Afrobrasileira e Indígena, oferecida pelo CBM-CEU; Introdução às Músicas do Mundo, oferecida pela UFRJ e História da Música Popular Brasileira, oferecida pela UNIRIO.

As entrevistas foram feitas entre o período de 27/07/2016 e 03/11/2016 em locais variados, dependendo da disponibilidade dos(as) entrevistados(as): nas próprias universidades, em uma lanchonete, em um evento de divulgação científica ou na residência de uma das entrevistadas. Todas as entrevistas foram gravadas com o auxílio de um notebook e de um celular, sendo totalizadas 7 horas, 18 minutos e 11 segundos de gravação. É muito importante ressaltar que, antes da gravação das entrevistas, os(as) entrevistados(as) foram informados(as) que seus nomes seriam guardados em sigilo, a fim de que eles(as) pudessem externar suas opiniões sem temer quaisquer prejuízos, e para tal, eles(as) poderiam escolher um pseudônimo para a identificação no texto da pesquisa. A seguir, tem-se o roteiro das entrevistas:

A primeira pergunta - Em que medida a disciplina que ministra influencia (ou influenciará) na prática docente do licenciando em Música que atua (ou atuará) na educação básica? - buscava auxiliar na compreensão de como os(as) docentes enxergam a importância da suas disciplinas na formação do(a) professor(a) de Música.

A segunda pergunta - Em sua opinião, quais são as capacidades e saberes principais a serem desenvolvidas na formação inicial do(a) professor de Música?- foi feita, na perspectiva de conhecer as principais capacidades que os(as) professores(as) julgam necessários à profissão de docente de Música. Parte-se do pressuposto de que tais capacidades citadas pelos(as) docentes são aquelas que eles(as) buscam gerar em seu alunado.

Caso a sensibilidade às diferenças culturais - ou algo semelhante - não fosse citada na resposta anterior, seria feita a terceira pergunta - Em que medida a sensibilização sobre a diversidade existente nas salas de aula do ensino básico é um aspecto importante da formação do(a) professor(a) de Música?

$\mathrm{Na}$ quarta questão - Como estes aspectos poderiam ser trabalhados em uma disciplina como a que o(a) senhor(a) leciona? - buscava-se compreender de que maneira 
os(as) professores(as) viam a possibilidade de trabalhar questões de interesse do multiculturalismo em suas disciplinas e como lidavam com tal questão na durante a prática docente.

A quinta questão - $O(A)$ senhor(a) acredita que os ritmos que são, em geral, preferidos pelos jovens em idade escolar no município do Rio de Janeiro - como o funk, o pagode, o hip hop, o rock etc. - devem ser usados pelo(a) professor(a) de Música da educação básica? Tais ritmos encontram espaço na instituição onde o(a) senhor(a) leciona? - foi cunhada tendo como referencia a pesquisa de Migon (2015) que, entre outros aspectos, analisou a preferência musical de discentes de uma escola pública do Rio de Janeiro, local onde também se delimita a presente pesquisa; e Penna (2012), que escreve sobre a importância da Educação Musical multicultural valorizar a musicalidade que os(as) discentes apresentam em suas vidas extraescolares, decidiu-se também arguir os(as) docentes formadores(as), a fim de analisar seus discursos sobre o tema.

A sexta pergunta - Na sociedade em geral, muitas vezes ocorre uma hierarquização entre música "erudita" e "popular". Em que medida essa hierarquização se faz presente em sua instituição? Caso ela exista, o(a) senhor(a) acredita que tal hierarquização influencia na formação dos professores de Música?- teve como objetivo verificar se os(as) professores(as) entrevistados percebem algum tipo de hierarquização de musicalidades na academia, visto que autores como Penna (2012) e Santiago e Monti $(2014,2016)$ afirmam que um ensino que prioriza a música "erudita" em detrimento da "popular" tende a desvalorizar um ensino multicultural.

A pergunta de número sete - De que forma a disciplina de Música na educação básica poderia contribuir para que os educandos percebam a diversidade como algo positivo?- visava compreender se os(as) docentes também viam a sensibilização às diferenças culturais como um possível objetivo da disciplina de Música quando ministrada na Educação Básica.

Já a oitava pergunta - Em que medida o(a) senhor(a) acredita que a formação de professores(as) da instituição que o (a) senhor(a) leciona está formando professores(as) de Música que podem evitar elou intervir positivamente em ocasiões de sexismos, homofobias, intolerâncias religiosas, bullyings etc.? - visava extrapolar a questão das diferenças musicais e tratar também de outras questões, como sexualidade, gênero, raça etc.; visto que autores(as) como Canen e Moreira (2001), Santiago e Ivenicki (2016a, 2016b) e Santiago e Monti (2016) apontam que uma das características de um currículo 
multicultural é não apenas inserir conteúdos de provinientes de diversas culturas como um mero adendo, mas também apontar e denunciar como os processos de desigualdade são cunhados, possibilitando na formação de pessoas críticas, conscientes e capazes de mudar tal realidade.

Com o objetivo de permitir que o(a) docente faça suas considerações finais, foi elaborada a nona pergunta - Por fim, quais são as suas necessidades para atender melhor a diversidade na sua disciplina e no curso em geral? - que também visava compreender se tal docente via outros aspectos ainda não citados como importantes para que sua instituição pudesse oferecer um ensino (ainda) mais voltado para a questão das diferenças.

Por fim, aponta-se que o material coletado foi bastante grande e, no presente artigo, se priorizará em apontar as ideias gerais e as categorias identificadas nos discursos, pois entendê-los pode possibilitar em uma melhor compreensão das dinâmicas das licenciaturas e sobre como as questões multiculturais estão presentes nelas. As falas dos(as) professores(as) que remetem a tais ideias gerais e categorias, quando necessárias, serão apontadas por meio de notas de rodapé. Iniciar-se-á, portanto, a análise das entrevistas dos(as) professores(as) do CBM-CEU.

\section{O que os(as) professores(as) do CBM-CEU têm a nos dizer sobre multiculturalismo?}

Os(as) docentes da instituição supracitada serão identificados como Fátima (Didática da Música), Ísis (Percepção Musical) e Lúcio (História da Cultura Afro-Brasileira e Indígena), teceram discursos favoráveis à presença das questões multiculturais na formação de professores(as) de Música, apesar de concordarem que, muitas vezes, tais questões são insuficientes ou não se fazem presentes nas formações.

A professora Fátima destacou a importância do(a) professor(a) formador(a) ser um exemplo para os(as) professores(as) em formação e tal exemplo de como lecionar deveria se dar por meio do respeito ao outro ${ }^{4}$. Porém, aparentemente, a sensibilização às questões culturais não deveria se constituir como objetivos específicos da Música, mas se dariam de

\footnotetext{
${ }^{4}$ Fátima: [A Música na educação básica] pode contribuir [para sensibilizar o alunado sobre questões multiculturais], a partir do momento que você respeita o repertório, respeita pelo gosto daquele aluno, você está dizendo: "eu te respeito".
} 
forma indireta, e viriam acopladas às discussões musicais quando o(a) professor(a) conseguisse transmitir tal respeito ${ }^{5}$.

A professora Ísis mostrou que temas socialmente relevantes podem ser tratados em disciplinas estritamente musicais, como Percepção Musical ${ }^{6}$. Levantou também a importância de se priorizar o relacionamento e a esfera afetiva entre docentes e discentes, levando em consideração não somente as diferenças culturais, mas também questões afetivas ${ }^{7}$.

O professor Lúcio, mostrou as dificuldades de lecionar uma disciplina de caráter inovador em um ambiente elitizado como uma faculdade de Música. Por sua atuação na militância negra, o docente focou sua fala na defesa desta identidade e apontou que existe um racismo inocente - ou seja, atitudes racistas que não são reconhecidas pelos seus agentes como tais - perpassando na esfera discente do curso de Licenciatura em Música do CBM-CEU; porém, mostrou também que uma disciplina como História da Cultura Afrobrasileira e Indígena é importante para que tal quadro possa ser revertido e para que pessoas que se identificam com a cultura negra se sintam representados no ambiente universitário $^{8}$, o que aponta para a importância da representatividade identitária na Educação.

No que se refere à questão da representatividade apontada pelo professor, Souza (2012) afirma que as questões condizentes às relações étnico-raciais devem também estar presentes na formação de professores - inclusive a continuada -, com o propósito de formar profissionais capazes de não apenas trabalhar com conteúdos provenientes da cultura negra de forma descontextualizada, mas também de abordarem tal temática continuamente e contextualizadamente, com o objetivo de desconstruir possíveis

\footnotetext{
${ }^{5}$ Fátima: Eu tenho um discurso radical (...) que a Música "não serve para nada". Eu detesto quando as pessoas falam "a Música é boa para disciplina, para fazer silêncio, para o vestibular, para memória, para matemática, para a coordenação motora, para a lateralidade". Nas minhas aulas quando o aluno prepara os planos de aula nos objetivos, eu quero somente objetivos musicais.

${ }^{6}$ Ísis: Acho que [as licenciaturas em Música] deveriam [formar professores(as) capazes de tratar das questões multiculturais em sala de aula]. Eu por exemplo, eu não perco essa oportunidade de discutir esses assuntos, mesmo na disciplina de Percepção Musical, porque eu sempre trago ritmos e eu coloco minhas experiências (...)

${ }^{7}$ Ísis: $[\mathrm{H}] \mathrm{oje}$ em dia eu acho fundamental, que é a questão da humanização dessa pessoa. Esse profissional ele tem que ser um ser humano, acima de tudo, humano, para olhar para o outro como humano. Você deve ser uma pessoa do afeto, olhar para o outro com afeto, porque existem realidades muito duras.

${ }^{8}$ Lúcio: O Conservatório [Brasileiro de Música] tinha uma demanda de alunos de classes populares muito grande, então o recorte raça, apesar de ter sofrido uma resistência, conseguiu cativar um público que estava vivendo nessa zona de fronteira (...) Muitos alunos que começaram a reconhecer potencialidades em sua própria história de vida, em sue cotidiano, em sua formação musical cruzada, a partir da disciplina. Era o cara que era o ogan do terreiro de macumba, o outro que aprendeu a tocar cavaco com o avô, o outro que participava do bloco, o outro que a mãe cantava...
} 
estereótipos e imagens negativas de negros, além de identifiar as diversas formas de preconceito que podem ocorrer no cotidiano escolar e intervir positivamente nesses casos.

Isso poderá propiciar aos(às) estudantes da Educação Básica um panorama geral da cultura africana e afrobrasileira, bem como um conhecimento sobre a situação dos negros na sociedade brasileira, nas sociedades africanas e no restante do mundo, logo, aponta-se a postura do professor como posituva, sob um olhar multicultural.

O tema da grande presença de discentes que professam o protestantismo, tanto na esfera universitária como na Educação Básica, foi abordado pelo professor e pelas duas professoras da instituição ${ }^{9}{ }^{10}$. Aparentemente, ensinar multiculturalmente com um público que muitas vezes se "fecha" em sua própria crença e cultura se constitui em um desafio, mas os(as) docentes apresentaram o diálogo como uma alternativa para superar tal impasse.

Quando o assunto tratado é religiosidade, tem-se mais um ponto a ser discutido: partindo do ponto que o aspecto religioso é também visto como divino, aquilo que é usado para a adoração tende a poder ser visto como santo, enquanto aquilo que é deixado de fora pode ser classificado como profano, impuro, indigno, demoníaco. Nessa perspectiva, argumenta-se que as musicalidades selecionadas para fazer parte do culto protestante também auxiliam na compreensão social sobre o que é santo e o que é profano.

Seguindo esta linha de pensamento, a música europeia pode ser considerada santa, por fazer parte do culto cristão, mas a música africana tem mais dificuldade de assim ser classificada, por ter menos espaço no cristianismo. Isso pode corroborar para a existência de estereótipos negativos ligados às musicalidades afro-brasileiras e africanas.

Tem-se também a questão identitária, visto que não se pode negar que o cristianismo (agora, alargando para outras vertentes, como o catolicismo) expressa uma identidade normativa e outras religiosidades, como as religiões de matriz africana, são tidas como

\footnotetext{
${ }^{9}$ Fátima: E aí também (...) em relação às igrejas evangélicas, quando os meus alunos se recusam, eles saem de sala de aula em um estágio aonde tem uma música que fale de Iemanjá. Então, o que eu acho que seria respeitoso apenas, se você não concorda, fique em silencio, não precisa ficar cantando e tal, mas você sair de sala de aula é você dizer: eu sou contra isso, então como você pode trabalhar a diversidade se você é contra e não está respeitando o que o aluno está fazendo ali?

${ }^{10}$ Lúcio: O Conservatório [Brasileiro de Música] tinha uma grande resistência nesse sentido, e tinha um dado também, uma dobra na problemática, que é a grande presença de alunos evangélicos, e isso era uma pedrada no calcanhar, pois a minha disciplina tinha uma discussão sobre raça, sobre cultura afro-brasileira, que passava pela problematização da diáspora africana em fim, e depois eu vinha trabalhando com aspectos da cultura, corpo, palavra, as expressões, então assim, você ia levar um vídeo sobre candomblé. Imagina: um cara que entrou na faculdade de Música a partir da igreja...os caras me achavam maluco.
} 
identidades marginalizadas e estereotipadas (McLAREN, 1997, HALL, 2003a, 2003b). Há portanto, um embate entre um grupo associado ao tradicionalismo manutenção da ordem social e outros que buscam reivindicar sues direitos de expressão e resistir à imposição cultural. Porém, não se pretende argumentar que as práticas normativas são, necessariamente, erradas e devem ser combatidas.

No geral, foi possível notar que muitas questões de interesse do multiculturalismo foram abordadas pelos(as) docentes, principalmente a questão da raça e religiosidade. Muitas dessas questões foram discutidas quando se conversava sobre a questão da presença de gêneros midiáticos, como o funk na escola e na formação de professores(as) de Música. Nenhum docente desta instituição foi contra a presença de tal musicalidade em um ambiente de Educação formal, porém, em geral, concordou-se sobre a existência da dificuldade de tal gênero musical - bem com de outros igualmente polêmicos - se tornar mais presente nas aulas de Música, por tratarem de questões delicadas, como sexualidade e violência.

Outros aspectos também foram citados como possíveis fatos que podem tanto impedir como impulsionar a uma maior presença das questões multiculturais na formação de professores(as), como a burocracia interna das próprias instituições no que se refere à aprovação de disciplinas que podem tratar de questões como raça, sexualidade, gênero ${ }^{11}$ etc.; e a fiscalização do Ministério da Educação, que, muitas vezes, exige o cumprimento de legislações e políticas multiculturais ${ }^{12}$.

Por fim, apesar do foco em questões como raça, religiosidade e sexualidade, pouco ou nada foi notado nas falas sobre questões como diferença de gênero, diferenças de concepção de sexualidade (heterossexualidade, homossexualidade entre outras) e etnia.

\footnotetext{
${ }^{11}$ Fátima: [A] gente tem que ter todo um jogo de cintura para poder "catequizar" o reitor para mostrar que essas questões são muito importantes. Por isso, eu acho que essas questões são muito difíceis (...).

${ }^{12}$ Afirmação baseada na seguinte afirmação do professor Lúcio: "Te confesso que até que o tema indígena não foi discutido (...) Esse é um outro plano da legislação. A gente até chegou a trabalhar alguns textos (...), [a] gente chegava a cumprir, para falar que a gente não fazia nada, demandas de conteúdos, trabalhava textos, trabalhávamos discussões, mas eu acho que não havia problema porque havia uma demanda (...) [o] Conservatório [Brasileiro de Música] tinha uma demanda de alunos de classes populares muito grande, então o recorte raça, apesar de ter sofrido uma resistência, conseguiu cativar um público que estava vivendo nessa zona de fronteira". Em outras palavras, o professor preferiu priorizar o tema raça ao tema etnia por ter muitos alunos negros na instituição.

Ísis: [Uma das razões para termos uma disciplina como História da Cultura Afro-Brasileira e Indígena é ] porque a fiscalização do Ministério da Educação é sempre muito maior nas faculdades privadas do que nas públicas. A Lei é para todas, mas você vai [sic] na UERJ, vai [sic] na UFRJ, aonde você vê a acessibilidade? E não tem, porque não tem fiscalização, eles próprios não se fiscalizam, mas eles vem fiscalizar o que não é deles [risos]. Como aqui tem fiscalização, nós somos obrigados a ter, porque se não perdemos o título de Centro Universitário, não conseguimos nos recredenciar se não atendermos todas as leis. Em universidades particulares com Música, você pode ter certeza que você vai encontrar.
} 
Sobre esse último aspecto, chamou à atenção a questão da existência de uma disciplina cujo nome aparentava tratar da questão indígena, que porém, na prática, não chegava a abordar profundamente tal assunto ${ }^{13}$.

Apesar de tais ênfases e omissões, tratam-se de três docentes cujos discursos apontavam para boas intenções em formar profissionais capazes de atuar positivamente em um ambiente plural como é a escola.

\section{O que os(as) professores(as) da UNIRIO têm a nos dizer sobre multiculturalismo?}

Os docentes da UNIRIO serão identificados como João (Didática da Música), Carlos (Percepção Musical) e Pietro (História da Música Popular Brasileira). Os discursos tratados pareceram decair de forma maciça na questão das diferenças musicais, deixando de lado outros tipos de diferença.

O professor João apresentou um discurso mais "compartimentalizado", no qual existiriam disciplinas certas para se tratar do tema das diferenças (como Etnomusicologia, Oficina de Música, disciplinas da Escola da Educação) e caberia à Didática da Música tratar de outras questões ${ }^{14}$. Assim como a professora Fátima (CBM-CEU), ele também mostrou-se contrário a questão da Música ter como objetivo sensibilizar o alunado para as questões multiculturais ${ }^{15}$.

Sobreira (2011, pp. 11-12), ao examinar historicamente as funções e justificativas da Música nas escolas regulares, deparou-se com as discussões sobre o uso da filosofia intrínseca e extrínseca, citadas pelo professor. A autora afirma que a Música, no momento atual, encontra espaço nas escolas justamente por seus objetivos extrínsecos e, nessa

\footnotetext{
${ }^{14}$ João: A PROM "um" ela prepara, nela você discute tudo isso, nas outras PROM's, por exemplo, você faz Orff [método de musiclização], mas você não vai discutir, por exemplo, a questão racial em uma aula de Orff, você vai discutir em disciplinas como Antropologia [Cultural], Educação Brasileira, na aula de Etnomusicologia, nas matérias da Educação, em Dinâmica Escolar, na PSIED que é Psiciologia da Educação, ou seja, em matérias que se tem um campo maior para se discutir isso, além das disciplinas relativas, por exemplo, às pessoas com deficiência, etc. A diversidade cultural perpassa em disciplinas eletivas que eles podem escolher, mas nas obrigatórias, algumas, por exemplo, como a própria Dino [Dinâmica e Organização Escolar], que é que elas fazem lá na [Escola de] Educação, ela já é voltada para isso. Então, na aula de musicalização em si, no Orff, eu não sei se eu vou ter momento assim para parar e dizer: "Ah, mas se o aluno for negro?" Entendeu? Acho que não existe o momento para fazer isso

${ }^{15}$ João: Você pode trabalhar esses diversos gêneros que eu estou te falando, só tem uma coisa que eu sou contrário, usar música para esse tipo de objetivo é não usar a Música como fim próprio (...) eu sou totalmente contrário aos objetivos não-estéticos da música, porque a filosofia intrínseca é a Música pela Música, então eu quero educar o aluno esteticamente, quero que ele toque, que ele cante, eu não quero que ele desenvolva a percepção fina, a lateralidade, que ele aprenda inglês, ou aprenda o que é diferente, a diversidade, isso são objetivos secundários, isso que a filosofia intrínseca diz, eu quero é formar a educação estética.
} 
perspectiva, negar as demandas sociais dos(as) discentes das escolas regulares e da sociedade em geral pode não colaborar para que a Música possa ser aceita nessa modalidade de Educação. Em complemento, tem-se a seguinte afirmação.

Percebe-se que a Filosofia Extrínseca tem sido a mais usada como argumentação a favor do ensino de música. Embora a maioria dos educadores musicais advogue que o ensino de música deva contemplar a imersão na música, considerando sua função "como um significante modo simbólico disponível aos indivíduos para expressar-se simbolicamente" (...), reconheço ser praticamente impossível fazer com que a sociedade aceite esta única finalidade. Além do mais, não creio que elas sejam excludentes (p. 11).

Em concordância com a autora, defende-se o "meio-termo" entre tais filosofias de Educação Musical. Se faz muito importante que a Música leve em consideração seus objetivos específicos, mas não se pode ignorar a quantidade de pontos positivos que esta traz consigo e que extrapola o nível musical. Propõe-se, portanto articular ambas vertentes para que de um ponto de vista multicultural seja possível se trabalhar a sensibilização às diferenças culturais também por meio da ministração dos conteúdos específicos de Música.

Por sua vez, o professor Carlos teve um discurso focado na questão do exemplo que o(a) professor(a) passa para a turma como uma estratégia para se formar profissionais sensíveis às diferenças ${ }^{16}$. Ele reconheceu a importância do tema da formação de professores(as) de música culturalmente sensíveis ${ }^{17} \mathrm{e}$, de forma semelhante ao professor João, ele vê com otimismo como a sua instituição trata de musicalidade "eruditas" e "populares"

Já o professor Pietro, diferentemente do professor João, reconhece a sensibilização às diferenças culturais como um objetivo da disciplina de Música e ele crê que sua disciplina contribui com a questão ao convocar os(as) discentes a contar e recontar suas próprias histórias, a partir de visões não-dominantes ${ }^{19}$. O docente também apontou a extensão

\footnotetext{
${ }^{16}$ Carlos: Eu acho que ao final das contas eu consigo de alguma maneira lidar com isso, ser sensível a isso e eu espero que isso sirva de alguma maneira (...), então eu acho que esse tipo de coisa, de atitude, de como você monta seu curso, isso reflete na forma que essas pessoas vão lidar como professores, em seus relacionamento com os outros.

${ }^{17}$ Carlos: Essas reflexões, essas necessidades de mudança em relação à inclusão, essas questões que estão aí e não podemos mais fingir que elas não aí, elas estão aí, e nós precisamos lidar com elas de alguma maneira (...) Acho que isso é uma coisa importante.

${ }^{18}$ Carlos: Acho que hoje em dia você tem menos [hierarquizações], isso tende a se diluir cada vez mais. Eu vejo até pelas práticas dos professores, os professores transitam pelas duas áreas [popular e erudito (...). Então esse racha existia na Música sim, uma coisa que é do século XIX, mas hoje em dia eu acho que tende a desaparecer.

${ }^{19}$ Pietro: Eu digo que na universidade a gente tem que ter uma outra postura, como alguém que faz parte do corpo da universidade, não ter uma visão de que eu sou o professor, vocês são os alunos, eu vou estar passando os conhecimentos, vocês vão estar anotando, não, e esse é um curso que te mais lacunas do que
} 
universitária como um possível modo de se tratar das questões multiculturais e citou como exemplo, a Escola Portátil de Música da UNIRIO, que se dedica ao ensino do choro.

De forma semelhante às entrevistas feitas no CBM-CEU, novamente, a feitura de novas legislações e burocracia acadêmica foi citada como uma incógnita ${ }^{20}$ que possibilita ou impede a presença de potenciais multiculturais nos cursos superiores.

Foi possível perceber que um diferencial do curso na UNIRIO é o apreço à música "popular"21", o que possibilita um fluxo de pessoas que detém diferentes categorias identitárias; porém, não se concorda que o simples fato de um local ser compartilhado por diferentes identidades garante que todos sejam respeitados em suas singularidades. Nessa perspectiva, os discursos dos(as) docentes acabaram por, na maioria das vezes, ficarerm restritos ao aspecto musical caracterizado pelo binarismo "popular"/“eudito", e pouco foi dito sobre diferenças de raça, etnia, sexualidade, gênero, religião etc.

\section{O que os(as) professores(as) da UFRJ têm a nos dizer sobre multiculturalismo?}

Os(as) professores(as) da UFRJ que cederam entrevistas serão identificados como Augusto (Didática da Música), Antonieta (Percepção Musical) e Felipe (Introdução às Músicas do Mundo).

Os professores Augusto e Felipe, teceram discursos favoráveis a presença das questões multiculturais na formação de professores(as) de Música; já a professora Antonieta mostrou-se conservadora em muitos pontos.

Augusto, apesar de concordar que todas as Músicas têm espaço no ensino de Música, apresenta que certas musicalidades que já são produzidas sem necessidade de formação acadêmica deveriam não ser integradas ao currículo como músicas a serem estudadas e ensinadas de forma musical, a fim de se manterem libertas do engessamento curricular. Ele

\footnotetext{
fatos concretos, então vocês precisam ajudar e a História da Música Popular Brasileira foi escrita sob determinados ângulos políticos e históricos e nós como músicos poderemos contribuir, não só para esse período, mas também hoje em dia, tentar fazer com que eles vejam que eles são agentes interativos nessa construção, e a reflexão sobre os textos, a gente vai estar sempre questionando o que não estará dito no texto, o que falta de informação.

20 Pietro: Então a gente tem que ter essa visão de que a música pode e deve [ter essa função de sensibilizar sobre as diferenças], mas ela como um artefato cultural pode ser usada de qualquer forma [positiva ou negativamente].

21 Tal direcionamento ao uso da música popular no curso de Licenciatura em Música da UNIRIO é também destacado em seu Projeto Político Pedagógico, que afirma que os contornos curriculares dos cursos de Licenciatura em Música e Bacharelado em Música Popular Brasileira são articulados, o que confere uma maior presença da música popular no curso de Licenciatura em Música da UNIRIO (UNIRIO, 2006).
} 
afirma também que a formação de professores(as) não deveria se focar em uma ou outra musicalidade, mas sim em formar egressos capazes de trabalhar com qualquer musicalidade que se apresentar nas aulas, e um possível caminho para isso seria por meio do arranjo e da composição ${ }^{22}$.

A professora Antonieta se mostrou mais tradicional. Apesar de reconhecer a necessidade de se incluir os mais diversos tipos de estudantes nas aulas de Música ${ }^{23}$, ela reproduziu muitos estereótipos que comumente são associados às músicas "populares" e midiáticas, como o hip-hop e o funk ${ }^{24}$. Por outro lado, mostrou-se deveras favorável ao ensino de Músicas folclóricas, cantigas de rodas e músicas "eruditas".

Por fim, o professor Felipe apontou que existem disciplinas na instituição que foram criadas para justamente atender às demandas pós-modernas, conscientizando e tratando não somente de questões multiculturais, mas também de outros temas sociais relevantes ${ }^{25}$. Porém, o professor lamenta que tais atitudes sejam impulsionadas somente pela área de

22 Augusto: Eu não tenho dúvidas que elas são como qualquer música disponíveis, acessíveis e desejáveis para o estudo. (...) Mas agora, ao mesmo tempo, um professor não consegue ser proficiente em todos os gêneros que existem, então eu não acho que seja o caso da gente incluir todos os gêneros de música como objeto de estudo durante a formação. Mais importante é a gente acessar vários desses como objeto de estudo e com isso ganhar a competência de lidar e de aprender novos gêneros que vão aparecer na sala de aula. Daqui há dez anos eu posso não estar lidando com o funk, eu preciso estar apto a aprender com os alunos.

${ }^{23}$ Antonieta: [Na] parte rítmica, nós somos bastante misturados, [tem-se] a influência africana, influência europeia por todos os lados, as coisas são muito ricas, agora o que eu tenho que influenciar? É o despertar do aluno para desenvolver a sua cultura...a sua cultura como professor, então ele tem que ter uma visão aberta para saber como ele vai preparar a aula dele, ele tem que ser eclético, ele não pode usar somente um tipo de exercício porque ele gosta, por exemplo, da cultura portuguesa, então ele só vai trabalhar músicas portuguesas, ritmos portugueses, não!

${ }^{24}$ Antonieta: Abomino isso tudo... Eu posso até utilizar o ritmo, mas eu não posso ficar botando o hip-hop, por que se não a minha aula vai virar o hip-hop, vai virar o funk. E que ritmo? É tudo a mesma coisa [tamtam-tam-tam-tam, percutindo a mesa], estou fazendo o quê? Nada! E a letra nem se fala. Nossa, mas tem tanta coisa na cultura brasileira, ricas! A gente tem que fazer o contrário, tem que mostrar para ela a cultura que ela não conhece! Cadê as letras saudáveis das brincadeiras de roda!?! Agora isso aí [músicas midiáticas] anula a capacidade de a pessoa pensar, porque é a mesma coisa repetida, repetida, repetida. E o professor tem que ter uma cultura muito ampla, até porque ficar na mesma coisa toda hora enche o saco. E esse hip-hop aí, na minha opinião não serve para nada, deveria ser proibido

${ }^{25}$ Felipe: Não foi só essa disciplina [Introdução às Músicas do Mundo] que foi criada para atender as discussões mais amplas de interesse mais ampla da sociedade, que de certa maneira, dialogam com o campo da Música, que perpassam o campo da Música. Tem outra disciplina que trata disso de maneira até mais pronunciada, que é a Introdução à Antropologia da Música [e a Pulsares]. Eu também sou professor delas, eu na verdade criei as duas. Essas duas disciplinas surgiram em uma reforma curricular, mais ou menos em 2001, 2002, justamente com o objetivo de abrir uma discussão sobre a diversidade, acima de tudo, que não se prendesse à música apenas da forma que ainda se faz: a forma dominante (...). 
Etnomusicologia de tal campus da universidade ${ }^{26}$ e que aspectos burocráticos internos da sua instituição impede que assuntos emergentes seja discutidos de forma aberta ${ }^{27}$.

É interessante ressaltar que o professor Augusto, cujas falas apontaram para um posicionamento favorável ao ensino de Música que considere as questões culturais, também está inserido nesse contexto da Etnomusicologia da UFRJ. Já a professora Antonieta que apresentou um discurso mais conservador, não faz parte desse contexto. Pode-se apontar a possibilidade de o grupo de Etnomusicologia da Escola de Música da UFRJ se constituir como uma forma de resistência a um certo tradicionalismo e conservadorismo da instituição, porém as atividades de tal grupo se apresentam como disciplinas optativas ou atividades de extensão que podem ou não ser cursadas pelos licenciandos, tornando a sensibilização às questões multiculturais como algo de caráter eletivo.

\section{Considerações Finais: Balanço}

Notou-se que, em geral, os(as) docentes das três instituições se mostraram favoráveis à adoção de currículos multiculturais, que busquem sensibilizar os(as) discentes sobre as diferenças culturais característica da Educação Básica e sobre as problemáticas acarretadas por esta.

Porém, foi possível identificar características que, segundo os(as) docentes, possibilitam, limitarm ou restringem a presença das questões multiculturais nos currículos ena formação de professores(as) de Música na cidade do Rio de Janeiro. No que se refere às questões que impulsionam ou embarreram a presença e/ou o tratamento de questões como raça, etnia, sexualidade, gênero etc., tem-se:

Professor(a) formador(a) como exemplo a ser seguido: Como já foi discutido, alguns(algumas) professores(as) afirmaram que se eles(as) próprios(as) durante suas práticas docentes demonstrarem que respeitam as diferenças existentes em suas classes,

\footnotetext{
${ }^{26}$ Felipe: [A Escola de Música da UFRJ] é a escola de Música mais conservadora do Brasil, que não é nenhuma "Brastemp”, mas pelo menos na Etnomusicologia nós temos tentado fazer a nossa parte, tanto na pesquisa quanto no ensino.

${ }^{27}$ Felipe: E não há realmente, assim um pensamento [sobre os conteúdos ensinados] no departamento da universidade, que quase sempre se restringe à estrutura burocrática da universidade. E as reuniões do Departamento de Musicologia e Educação Musical da universidade sobre assuntos pedagógicos não podem ser misturadas em uma reunião de duas horas com questões administrativas, como promoção de docentes, viagens, processos de alunos sobre questões de equivalência. Esse espaço é cada vez menor e as discussões sobre conteúdos, isso tudo é muito atropelado. Nós fazemos esse tipo de discussão no corredor, privadamente, pois não temos esse tipo de discussão de forma sistemática.
} 
estaría-se exemplicando aos(às) professores(as) em formação a forma na qual eles(as) devem agir e suas (futuras) práticas docentes.

Argumenta-se que, possivelmente, a questão do "exemplo" agindo isoladamente pode não ser suficiente para conscientizar e sensibilizar sobre a importância do apreço às diferenças e sobre as problemáticas de questões como racismos, preconceitos, discriminações, sexismos, intolerâncias religiosas, xenofobias, bullyings etc., e, nessa perspectiva, seria necessária a ministração de conteúdos que tratassem diretamente da questão. Tal tipo de pensamento foi levantado pela professora Fátima (CBM-CEU), Carlos (UNIRIO) e Augusto (UFRJ) de formas muito semelhantes, sendo que o diálogo foi considerado um aspecto deveras importante neste processo.

Religiosidade protestante: Tal aspecto também foi discutido, e se refere à dificuldade de se tratar de certos temas, como religiosidades de matriz africana, sexualidade, gênero etc., com discentes protestantes, que, em alguns casos, consideram algumas práticas que fogem da normatividade como pecados. Esta questão foi apontada pela professora Adriana (CBM-CEU), Ísis (CBM-CEU), Lúcio (CBM-CEU) e Felipe (UFRJ). Nessa perspectiva, as dificuldades de se trabalhar tais questões com os(as) estudantes foram superadas, em alguns casos, por meio da dismitificação das práticas musicais, ou seja, pela afirmação de que o curso não deseja “catequizar ningém" e que "um ritmo é só um ritmo", visto que não há nada de essencialmente sagrado ou profano em práticas musicais.

Hieraraquias sociais reproduzidas pela academia: Foi argumentado que as hierarquizações e discriminações que muitas vezes são verificadas na formação de professores(as) de Música são reproduções do que ocorre na sociedade. Este pensamento esteve presente nos discursos da professora Fátima (CBM-CEU), João (UNIRIO) e Felipe (UFRJ) e colocam em dúvida sobre até qual ponto seria possível se estabelecer um curso de formação de professores(as) de Música multiculturalmente orientado em uma sociedade que não pratica justiça social. Pode-se pensar que a universidade pode colaborar para a mudança na sociedade e não esperar para que o inverso ocorra.

Manutenção de políticas públicas de acesso e permanência no ensino superior: Políticas promulgadas durante os governos Lula e Dilma (como o REUNI e o PROUNI) foram elogiadas, por aumentarem o acesso e a democratização do ensino superior, possibilitando que pessoas de diferentes origens tenham possibilidade de estudar em uma instituição pública de ensino. Nessa perspectiva, alguns professores crêem que tais 
políticas possuem caráter multicultural e se sentem temerosos que elas venham a ter um fim. Os professores que assim afirmaram foram Carlos (UNIRIO), Augusto (UFRJ) e Felipe (UFRJ).

Pressões de âmbito superior e Burocracia acadêmia: Alguns(algumas) docentes apontam que as inspeções do MEC e questões administrativas das próprias universidades podem corroborar ou impedir um atendimento mais focado para questões multiculturais. Foram citados vários exemplos, como a questão de disciplinas que possam tratar de questões multiculturais serem vistas como menos rentáveis pelas universidades privadas (Fátima, CBM-CEU), o fato das mudanças acadêmicas serem lentas e dependentes de aprovações do Ministério da Educação (Pietro, UNIRIO), e o fato das reuniões de departamento se focarem em questões estruturais da universidade, deixando de lado questões educacionais (Felipe, UFRJ), e o fato das inspeções do MEC forçarem instituiões a criarem disciplinas multiculturais (Ísis, CBM-CEU)

Pluralidade da instituição: É interessante notar que professores que não apontam para a existência de uma hierarquia entre música "popular" e "erudita" em suas instituições e também crêem que em suas instituições existe uma valorização das diferenças, exemplificam tal fato por meio da afirmação de que em suas instituições existem pessoas de perfis variados.

Em uma perspectiva como esta, a presença de diferentes pessoas em um mesmo local expressaria uma harmonia natural, porém, se argumenta que é justamente em locais plurais que existem choques de culturas, relações de poder e hierarquias culturais. Tal categoria foi identificada nos discussos dos professores João (UNIRIO) e Carlos (UNIRIO).

Música pela Música (objetivos estéticos): Também foi apontado pela professora Adriana (CBM-CEU) e João (UNIRIO) que a Música enquanto disciplina escolar, não deveria ter objetivos que fugissem do musical (como, por exemplo, a sensibilização às diferenças culturais) e argumenta-se que isso pode afetar negativamente a presença de questões multiculturais tanto na formação de professores(as) e na disciplina de Música quando oferecida na Educação Básica.

Importância da disciplina de Estágio Curricular Supervisionado para tratar de questões multiculturais: A disciplina citada apareceu em recorrentemente em algumas falas, Adriana (CBM-CEU) e João (UNIRIO), e de forma um pouco mais indireta pelo professor Felipe (UFRJ), apontando que se espera que ela seja um tempo e espaço propícios para se tratar de questões como bullyings, preconceitos e discriminações que 
podem ocorrer no "chão da escola". Porém, argumenta-se que um "peso" de responsabilidade tão grande não deveria recair sobre uma única disciplina (SANTIAGO; IVENICKI, 2016a).

Compartimentalização, transversalidade e interdisciplinaridade: Diferentes "tratamentos curriculares" foram percebidos nos discursos docentes. A professora Antonieta (UFRJ) ao mesmo tempo que apresentou traços de compartimentalização ("não vou entrar por aqui pois é a matéria do meu colega”), também afirmou que sua disciplina "conversa" com todas as outras do currículo, o que aponta para uma perspectiva interdisciplinar. Argumenta-se que tais características da disciplina favorecem a possibilidade desta tratar de temas de interesse do multiculturalismo. O discusso do professor João (UNIRIO) foi essencialmente voltado à compartimentalização curricular, apontando várias vezes que existem disciplinas "certas" para se tratar de cada tema. Tal tipo de discurso foi verificado de forma mais sutil na entrevista do professor Augusto (UFRJ). Houve também professores(as) que argumentaram que suas disciplinas podem tratar, sem prejuízos, de temas multiculturais, o que expressa que tais conteúdos seriam como temas transversais. Isso foi verificado nas entrevistas dos(as) seguintes professores(as): Fátima (CBM-CEU), Lúcio (CBMCEU), Ísis (CBM-CEU) e Felipe (UFRJ).

Afirma-se que, talvez, a compartimentalização não seja a melhor estratégia curricular para se tratar das questões multiculturais, pois aglutinaria tais discussões e algumas disciplinas, possivelmente optativas e desconectadas do restante do currículo (SANTIAGO; IVENICKI, 2016a).

Arranjo e Composição: Os professores João (UNIRIO) e Augusto (UFRJ) apontaram que o arranjo e a composição podem ser possíveis caminhos poderão auxiliar os(as) professores(as) em formação para lidar com qualquer musicalidade que aparecer nas salas de aula da Educação Básica.

Ritmos midiáticos como elemento musical ou objeto de pesquisa?: Algumas entrevistas, como a entrevista da Adriana (CBM-CEU), Ísis (CBM-CEU), Lúcio (CBMCEU), João (UNIRIO) e Pedro (UNIRIO), apontaram para a total possibilidades de se trabalhar com gêneros midiáticos, como o funk e o hip-hop, na formação de professores(as) por meio da exploração das suas características musicais.

Já os(as) professores(as) Carlos (UNIRIO) e Augusto (UFRJ), por afirmarem que tais ritmos são bem representados na sociedade em geral, poderiam achar seu espaço na 
academia por meio de pesquisas de cunho etnomusicológico. É interessante também notar que os professores Lúcio (CBM-CEU) e Pietro (UNIRIO) afirmam que ritmos midiáticos, como o funk, já são bem estudadas na academia, mas não no contexto da Educação Musical. Já a professora Antonieta (UFRJ), por sua vez, não concebe a possibilidade de tais ritmos adentrarem no espaço acadêmico.

Papel da extensão universitária: Embora hajam poucos (talvez nenhum) trabalhos que relacionem extensão universitaria com as questões multiculturais em educação musical, tem-se que os professores Pietro (UNIRIO) e Felipe (UFRJ) apontarem tais espaços com propícios para se tratar do tema.

Papel dos(as) estudantes em possíveis mudanças da universidade: Tem-se também que os(as) discentes também são chamados para a responsabilidade de cobrar para que mudanças sejam realizadas na universidade. Nessa perspectiva, o professor Pietro (UNIRIO) e o professor Felipe (UFRJ) apontam que os(as) os professores(as) em formação também têm papel nessa história, seja recontando histórias contadas por ângulos eurocêntricos e/ou cobrando mudanças na universidade por meio de organizações discentes.

De forma mais sutil, tem-se também questões como: a necessidade da Educação levar em consideração questões de cunho emotivo e subjetivas (Ísis, CBM-CEU), a necessidade da ampliação do conceito de Música (Lúcio, CBM-CEU), a valorização das potências corporais (Lúcio, CBM-CEU), o cuidado ao perfil de um alunado com insuficiências em certos conceitos e habilidades musicais (Carlos, UNIRIO), o ato de se valorizar mais as semelhanças do que as diferenças (Carlos, UNIRIO), a existência de um número maior de fontes históricas de músicas "eruditas" do que de músicas "populares" (Pietro, UNIRIO), uso de material didático com músicas de diversos países (Antonieta, UFRJ) e a pouca produção acadêmica sobre multiculturalismo e Educação Musical (Felipe, UFRJ).

Nessa perspectiva, aponta-se que tais categorias podem ser utilizadas a fim de se entender melhor como se dá a formação de professores(as) de Música e como tais profissionais estão sendo formados para enfrentar os desafios que as diferenças culturais impõem nas escolas regulares.

Porém, destaca-se que questões identitárias como gênero, sexualidade, faixa geracional, identidade indígena e o combate ao bullying estiveram muito pouco presentes nos discursos docentes, expressando que os aspectos multiculturais que mais transitam no 
cotidiano acadêmico de Música são a raça e o binarismo entre a musicalidade "erudita" e "popular", porém ressalta-se que, apesar de tais tópicos serem importantes, argumenta-se que eles sozinhos não são suficientes para tratar de forma plena o tema das diferenças.

Se fazem necessários, portanto, maiores esforços para que diversas categorias identitárias se vejam representadas pelos currículos da formação de professores(as), o que poderá contribuir para que os(as) docentes em formação se tornam mais aptos(as) a ensinar em ambientes plurais.

Porém, não se pode negar que a maioria das atitudes dos(as) professores(as) aqui tratadas são positivas e buscam valorizar as diferenças em suas instituições, e qualquer atitude positiva deve ser incentivada e elogiada.

\section{Referências}

ALVARENGA, C.; MAZZOTTI, T. B. Educação musical e legislação: reflexões acerca do veto à formação específica na Lei 11.769/2008. Opus, Porto Alegre, v. 17, n. 1, p. 51-72, jun. 2011.

BATISTA, A. C. L.; SILVA JUNIOR, P. M; CANEN, A. Em busca de um dialogo entre Plano Nacional de Educação (PNE), Formação de professores e multi/interculturalismo. Ensaio: Avaliação de Políticas Públicas em Educação, Rio de Janeiro, v. 21, n. 79, p. 253-267, abr./jun. 2013.

BONI, ; QUARESMA, S. J. Aprendendo a entrevistar: como fazer entrevistas em Ciências Sociais. Revista Eletrônica dos Pós-Graduandos em Sociologia Política da UFSC, 2005

CANEN, A.; MOREIRA, A. F. B. Reflexões sobre multiculturalismo na escola e na formação docente. In Canen, A.; Moreira, A. F. B. Ênfases e omissões no currículo. Campinas: Papirus Editora, 2001

.; ANDRADE, L. T. Construções Discursivas sobre Pesquisa em Educação: o que dizem a professores formadores universitários. Educação \& Realidade, Porto Alegre, v. 30, n.1, p. 49-65, 2005.

; ARBACHE, A. P.; FRANCO, M. Pesquisando Multiculturalismo e Educação: o que dizem as dissertações e teses. Educação \& Realidade, Porto Alegre- RS, v. 26, n.1, p. 161-181, 2001.

COUTO, A. C. N.; SANTOS, I. R. S. Por que vamos ensinar Música na escola? Reflexões sobre conceitos, funções e valores da Educação Musical Escolar. Opus, Goiânia, v. 15, n. 1, p. 110-125, jun. 2009.

CUNHA, S. D; LOMBARDI, S. S. L; CISZEVSKI, W. S. Reflexões acerca da formação musical de professores generalistas a partir dos princípios: "os quatro pilares da educação" 
e "educação ao longo de toda a vida". Revista da ABEM, Porto Alegre, V. 22, 41-48, set. 2009.

FIGUEIREDO, S. L. F; MEURER, R. P. Educação musical no currículo escolar: uma análise dos impactos da Lei no 11.769/08. Opus, v. 22, n. 2, p. 515-542, dez. 2016

FURQUIM, A. S. S.; BELLOCHIO, C. R. A formação musical de professores unidocentes: um estudo em cursos de pedagogia do Rio Grande do Sul. Revista da ABEM, Porto Alegre, v. 24, 54-63, set. 2010.

HALL, S. A centralidade da cultura: notas sobre as revoluções culturais do nosso tempo. Educação \& Realidade, Porto Alegre, v. 22, nº2, p. 15-46, jul./dez, 2003a

UFMG, 2003b

Da diáspora: identidades e mediações culturais. Belo Horizonte: Editora da

JÚNIOR, J. F. S. Q; COSTA, F. S. Pibid e a formação inicial de professores de música no Brasil: uma análise exploratória. Revista da ABEM, Londrina, v.23, n.35, 35-48, jul.dez, 2015

LAZZARIN, L. F. Multiculturalismo e multiculturalidade: recorrências discursivas na educação musical. Revista da ABEM, Porto Alegre, v. 19, p. 121-128, mar., 2008.

. A dimensão multicultural da nova filosofia de educação musical. Revista ABEM, Porto Alegre, V. 14, 125-131, mar. 2006.

LEMOS, M. S. Música nas escolas: ações da Funarte em prol da implementação da Lei 11.769. Revista da ABEM, Porto Alegre, v. 24, 117-120, set. 2010.

McLAREN, P. Multiculturalismo Crítico. São Paulo: Cortez, 1997.

MIGON, C. A. Possibilidades e limites de uma apreciação musical multi/intercultural nas escolas. Rio de Janeiro, 2015. Dissertação (Mestrado em Educação) Universidade Federal do Rio de Janeiro (UFRJ), Rio de Janeiro, 2015.

PENNA, M. Música(s) e seu ensino. Porto Alegre: Sulina, 2012

Poéticas musicais e práticas sociais: reflexões sobre a educação musical diante da diversidade. Revista da ABEM, Porto Alegre, V. 13, 7-16, set., 2005

Desafios para a educação musical: ultrapassar oposições e promover o diálogo. Revista da ABEM, Porto Alegre, V. 13, 35-43, mar. 2006.

A Lei 11.769/2008 e a música na educação básica: quadro histórico, perspectivas e desafios. InterMeio:: Revista do Programa de Pós-Graduação em Educação-UFMS, v. 19, n. 37, p. 53-75, 2013.

QUEIROZ, L. R. S. Música na escola: aspectos históricos da legislação nacional e perspectivas atuais a partir da Lei 11.769/2008. Revista da ABEM, Londrina, v.20, n.29, 23-38, jul.dez, 2012 
REQUIÃO, L. Educação Musical em escolas da Costa Verde Sul Fluminense: problematizando possibilidades de implementação da Lei.11.769/2008. Revista da ABEM, v. 21, p. 91-102, 2013.

SANTIAGO, R. Música, Educação Musical e multiculturalismo: uma análise da formação de professores(as) em três instituições de ensino superior da cidade do Rio de Janeiro. Dissertação (Mestrado em Educação). Faculdade de Educação, Universidade Federal do Rio de Janeiro, Rio de Janeiro, 2017.

SANTIAGO, R. ; MONTI, E. M. G. Um olhar multicultural: algumas contribuições para a atuação do professor de música da educação básica. Travessias (UNIOESTE. Online), v. 10, p. 73-88, 2016

.; IVENICKI, A. Multiculturalismo na formação de professores de música: o caso de três instituições de ensino superior da cidade do Rio de Janeiro. Opus (Belo Horizonte. Online), v. 22, p. 170, 2016c

Multiculturalismo como política de inclusão/exclusão. Revista Nuances: Estudos sobre Educação, v. 27, p. 279-299, 2016 b.

SOBREIRA, S. Reflexões sobre a obrigatoriedade da música nas escolas públicas. Revista da ABEM, Porto Alegre, V. 20, 45-52, set. 2008.

.; A disciplinarização do ensino de Música e as contingências do meio escolar. Per Musi, Belo Horizonte, n.26, 2012, p.121-12

SOUZA, J. et al. Audiência Pública sobre políticas de implantação da Lei Federal no 11769/08 na Assembleia Legislativa do Rio Grande do Sul. Revista da ABEM, Porto Alegre, V. 23, 84-94, mar. 2010.

SOUZA, M. E. V. Relações raciais e educação: desafios e possibilidades para a formação continuada do professor. Revista da Educação Pública. Cuiabá v. 21 n. 46 p. 289-301 maio/ago. 2012.

UNIVERSIDADE FEDERAL DO ESTADO DO RIO DE JANEIRO. Projeto PolíticoPedagógico - Proposta de Alteração Curricular, 2006. Acesso em 08/12/2018, disponível em http://www2.unirio.br/unirio/cla/ivl/cursos/graduacao/licenciatura-emmusica/licenciatura_projeto_pedagogico_ivl_unirio.pdf.

WOLFFENBÜTTEL, C. R.; ERTEL, D. I.; SOUZA, J. V. Música nas escolas: uma investigação sobre a implementação nos municípios do Rio Grande do Sul. Revista Música Hodie, v. 16, p. 165-183, 2016.

Recebido em: 06.08.2017

Aceito em: 05.12.2018 